\section{Disrupción esternal sin existencia de fractura tras traumatismo torácico}

\section{Sr. Director:}

El incremento en incidencia de traumatismos en el área esternal se debe en el momento actual a un aumento en los accidentes de tráfico, frecuentemente secundarios a impactos de alta energía (a menudo choque frontal contra otro vehículo). Más de un $8 \%$ de los pacientes con traumatismo torácico posee fracturas en el área esternal originadas en su mayor parte por colisiones contra el volante o por lesiones producidas por el cinturón de seguridad o por el airbag (1). La mayoría de las fracturas esternales ocurren en el cuerpo del esternón $(77 \%)$, sin observar desplazamiento de las mismas en el $75 \%$ de las ocasiones (2). Sin embargo la existencia de traumatismos en esta zona sin coexistencia de fractura no constituye un hecho frecuente. A continuación exponemos nuestra experiencia en este tema.

Paciente de 74 años de edad ingresado en UCI debido a una fractura de pelvis y un traumatismo torácico tras ser aplastado por un objeto de 2 toneladas de peso. Ingresa intubado y bajo efectos de sedación. En la exploración inicial además de un volet costal y fracturas de las cuatro ramas pelvianas, destaca una gran deformidad en el área esternal. Se realiza una tomografía axial computarizada (TAC) helicoidal urgente donde además de múltiples fracturas costales derechas a varios niveles, se aprecia una desalineación del cuerpo con el manubrio esternal, siendo únicamente mediante la reconstrucción coronal de la imagen obtenida en la TAC, donde se puede evidenciar una afectación de las partes blandas adyacentes sugestiva de hematoma sin existencia de una línea de fractura (Figs. 1 y 2).

Los traumatismos esternales se asocian hasta en un $80 \%$ a traumatismos a otros niveles, y cuentan con una considerable mortalidad -cifrada alrededor del 12\%-, tanto en el lugar del accidente como intrahospitalaria $(1,2)$. La mayoría de las lesiones esternales se producen en el cuerpo del esternón y se trata de fracturas transversales de sencillo diagnóstico mediante radiografías en proyección lateral (3). Determinadas lesiones del esternón, como la mencionada en el presente caso clínico, así como fracturas verticales, y anomalías en la unión condrocostal y del manubrio esternal, a menudo solo se detectan mediante la recons-

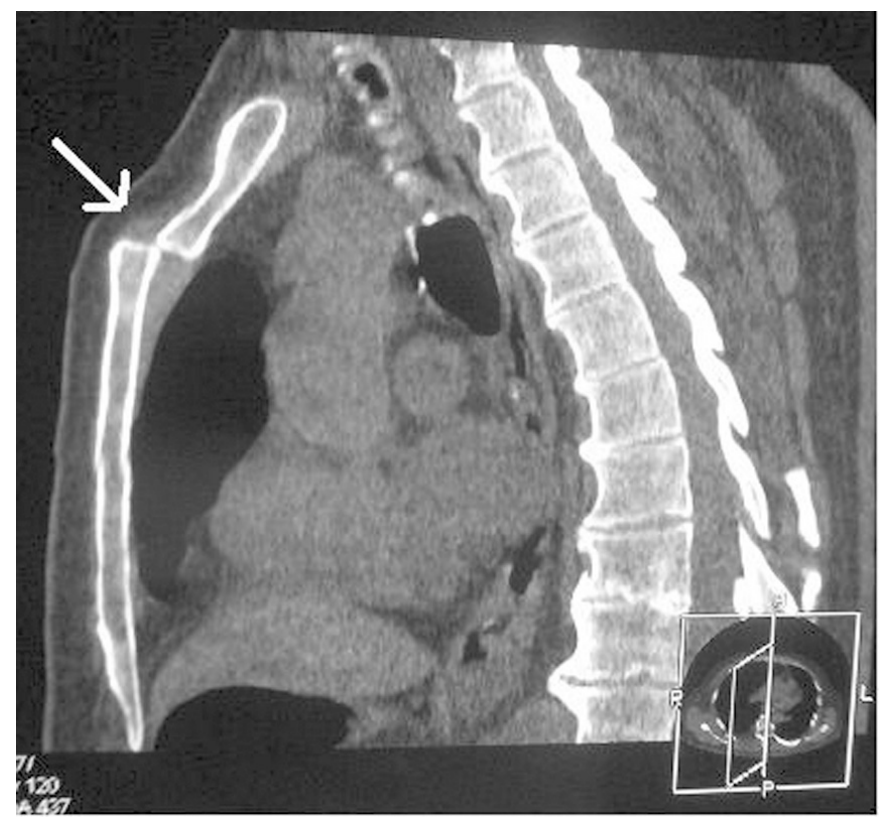

Fig. 1. TAC helicoidal: desalineación del cuerpo con el manubrio esternal.

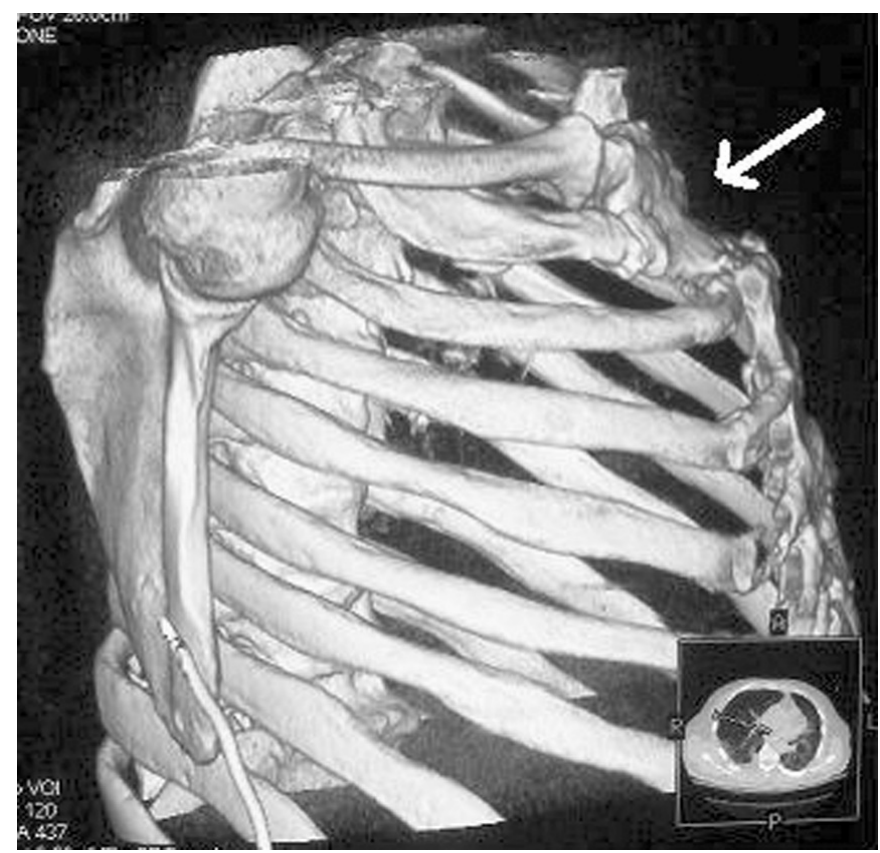

Fig. 2. Reconstrucción coronal: afectación de las partes blandas adyacentes correspondiente a un hematoma.

trucción coronal de imágenes obtenidas mediante una TAC torácica $(4,5)$. Aunque existen estudios donde se comunica que también la ultrasonografía puede resultar útil para el diagnóstico de fracturas esternales debido a su fácil disponibilidad y nula invasividad (6), el empleo de técnicas de imagen para el diagnóstico de las lesiones esternales es un tema controvertido (4). En ocasiones, cuando existe una sospecha de este tipo de lesiones que no puede ser objetivada mediante estudios convencionales, se recomienda la realización de una TAC torácica con imágenes reconstruidas como técnica de elección (4,7-9).

\section{B. Obón Azuara, I. Gutiérrez Cía, B. Villanueva Anadón, F. Pardo Camacho}

Servicio de Medicina Intensiva. Hospital Clínico Universitario. Zaragoza

1. Knobloch K, Wagner S, Haasper C, Probst C, et al. Sternal fratures occur most often in old cars to seat-belted drivers without any airbag often with concomitant spinal injuries: Clinical findings and thecnical collision variables among 42,055 crash victims. Ann Thorac Surg 2006; 82: 444-50.

2. Von Garrel T, Ince A, Junge A, Schnabel M, Bahrs C. The sternal fracture: Radiographic analysis of 200 fractures with special reference to concomitant injuries. J Trauma 2004; 57: 837-44.

3. Velutini JA, Tarazona PF. Fracture of the manubrium with posterior displacement of the clavicle and first rib. A case report. Int Orthop 1998; 22: 269-71

4. Ayrik C, Cakmakci H, Yanturali S, Ozsarac M, Ozucelik DN. A case report of an unusual sternal fracture. Emerg Med J 2005; 22: 591-3.

5. Collins J. Chest wall trauma. J Thorac Imaging 2000; 15: 112-19.

6. Engin G, Yekeler E, Guloglu R, Acunas B, Acunas G.n US versus conventional radiography in the diagnosis of sternal fractures. Acta Radiol 2000; 41: 296-9.

7. Kehdy F, Richardson JD. The utility of 3-D CT scan in the diagnosis and evaluation of sternal fractures. J Trauma 2006; 60: 635-6.

8. Nakae H, Tajimi K, Kodama H. Diagnosis of a fractured manubrium aided by three-dimensional computed tomographic scanning. J Trauma 2003; 55: 139-40.

9. Saab M, Kurdy NM, Birkinshaw R. Widening of the mediastinum following a sternal fracture. Int J Clin Pract 1997; 51: 256-7. 